\title{
Uma pedagogia dos gêneros orais para a educação infantil
}

\section{Evangelina Maria Brito de Faria Marianne C. B. Cavalcante}

Doutora, Professora Adjunta do Programa de

Pós-Graduação em Linguística (PROLING) da

Universidade Federal de Paraíba (UFPB). Projeto

A construção da textualidade na fala infantil

CNPq. Proc. No 400758/2007-5

\section{Resumo: Pesquisas recentes têm colocado em} relevo a necessidade do ensino dos gêneros orais nas instituiçōes escolares. Esse assunto ainda tem um toque de novidade nos livros didáticos e, principalmente, entre os professores que atuam na Educação Infantil. Ao analisarmos algumas aulas gravadas na pré-escola, percebemos que a oralidade ainda é vista como um meio para a aquisição da escrita e tem como única estratégia para o seu desenvolvimento o momento da roda, em que alguns alunos falam do que aconteceu no dia anterior ou contam histórias. As perguntas que nortearam nosso artigo foram: $a$ oralidade deve ser encarada como objeto autônomo de trabalho escolar já na Educação Infantil? Os gêneros orais respondem metodologicamente ao trabalho com a oralidade? Para tentar responder, partiremos inicialmente da visão do Referencial para a Educaçáo Infantil sobre esse assunto e, com base nas teorias aquisicionais $e$ nos pressupostos teóricos de Marcuschi (2002) e de Schneuwly (2004), analisaremos dados coletados no pré-escolar, apontando os gêneros como metodologia para o ensino do oral já na Educaçăo Infantil.

Palavras- chave: gêneros, oralidade, Educação Infantil
Doutora, Professora Adjunta do Programa de Pós-Graduação em Lingüistica (PROLING) Universidade Federal da Paraiba (PB)
Abstract: Recent researches have placed emphasis on the need for education of oral genres in schools. This issue still has a touch of novelty in textbooks and, especially, among the teachers who serve in Early childhood education. In reviewing some lessons recorded in the preschool, we noticed that the oral is still seen as a means for the acquisition of written and has the unique strategy for their development time of the wheel, where some students speak of what happened the previous day or tell stories. Questions that guided our article were: the oral should be seen as standalone object of school work, as in early childhood education? Genera oral respond methodologically to work with the oral? To try to respond, we begin the vision of reference for early childhood education on the matter and based on acquisition theories and the theoretical assumptions of Marcuschi (2002) and Schneuwly (2004), review data collected in the pre-school, pointing the genres like methodology for the teaching of oral already in early childhood education.

Key-words: genres; oral; early childhood education. 



\section{Introdução}

Trabalhando na área da aquisição de linguagem, é natural nosso interesse por todos os aspectos de linguagem presentes na Educação Infantil. Porém, um em particular tem chamado nossa atenção: a oralidade. Com o desenvolvimento das pesquisas sobre os gêneros orais, foi natural querer saber, por um lado, como a fala é vista pelo discurso oficial e, por outro, como é trabalhada na sala de aula do pré-escolar. Após essa discussão, procuraremos ver, metodologicamente, se os gêneros podem ser introduzidos e quais gêneros se adaptam ao nível das crianças nessa faixa etária. Comecemos pela visão do discurso oficial sobre o ensino da oralidade.

\section{A oralidade no Referencial Curricular para a Educação Infantil}

O domínio da língua oral e escrita é fundamental para a participação social efetiva, pois é por meio dela que o homem se comunica, tem acesso à informação, expressa e defende pontos de vista, partilha ou constrói visões de mundo, produz conhecimento. O Ministério da Educação, tendo em vista essas ideias, ao consolidar os Parâmetros, apontou metas de qualidades que ajudassem o aluno a enfrentar o mundo como cidadão participativo, reflexivo, conhecedor de seus direitos e deveres' ${ }^{1}$. O Referencial Curricular para a Educação Infantil constitui-se

em um conjunto de referências e orientações pedagógicas que visam a contribuir com a implantação ou implementação de práticas educativas de qualidade que posam promover e ampliar as condições necessárias para o exercício da cidadania das crianças brasileiras. Sua função é contribuir com políticas e programas de educação infantil, socializando informações, discussões, subsidiando o trabalho educativo de técnicos, professores e demais profissionais da educação infantil e apoiando os sistemas de ensino estaduais e municipais (p13).
${ }^{1}$ Comentaremos apenas as diretrizes do Referencial para a Educação Infantil para o ensino da oralidade. 
Essas orientações são resultado de reflexões, pesquisas e experiências de vários pesquisadores que, conjuntamente, procuram ver o desenvolvimento da criança por diferentes ângulos: da motricidade, do linguístico, cognitivo, social, emocional. Para cobrir esses diferentes ângulos, estruturaram o documento da seguinte forma:

a) Um documento de introdução, que apresenta os objetivos gerais da educação infantil e orienta a organização dos eixos de trabalho, que estão agrupados em dois temas: Formação Pessoal e Social e Conhecimento de Mundo;

b) Um volume direcionado à Formação Pessoal e Social que procura favorecer a construção da Identidade e da Autonomia da criança;

c) Umvolumerelativoà experiência Conhecimento de Mundo que contém seis documentos referentes aos eixos de trabalho orientados para a construção das diferentes linguagens pelas crianças e para as relações que se estabelecem com os objetos de conhecimentos: Movimento, Música, Artes Visuais, Linguagem Oral e Escrita, Natureza e Sociedade e Matemática.

Gostaríamos de chamar atenção para o título do eixo de trabalho Linguagem oral e escrita, em que se pode perceber que também as diretrizes do Referencial Curricular colocam a oralidade em relação de igualdade com a escrita, abrindo caminhos para o tratamento da linguagem como ação social, reafirmando o continuum das práticas sócio-interacionais que se estabelecem na e pela linguagem. Essa nova visão direciona o ensino de língua para uma outra abordagem em substituição ao antigo domínio da escrita.

É uma visão que conduz ao tratamento do uso da língua como competência comunicativa, que permite que se inicie, em relação à oralidade, pelas noções básicas da organização da língua na interação cotidiana para se 
chegar aos usos orais formais e públicos, tendo em mente as características linguísticas da produção oral (formais e informais) e as diversas relações que se estabelecem entre língua falada e língua escrita.

No Referencial, destacamos as indicações para o trabalho com a oralidade com crianças de quatro a seis anos, em relação ao falar e escutar:

1. Uso da linguagem oral para conversar, brincar, comunicar e expressar desejos, necessidades, opiniões, ideias, preferências e sentimentos e relatar suas vivências nas diversas situações de interação presentes no cotidiano.

2. Elaboração de perguntas e respostas de acordo com diversos contextos de que ele participa.

3. Participação em situações que envolvam a necessidade de explicar e argumentar suas ideias e pontos de vista.

4. Relato de experiências vividas e narração de fatos em sequência temporal e causal.

5. Reconto de histórias conhecidas com aproximação às características da história original no que se refere à descrição de personagens, cenários e objetos, com ou sem ajuda do professor. 6. Conhecimento e reprodução oral de jogos verbais como: trava-línguas, parlendas, adivinhas, quadrinhas, poemas e canções (RC: P. 137).

Mais adiante, o Documento afirma:

é importante planejar situações de comunicação que exijam diferentes graus de formalidade, como conversas, exposições orais, entrevistas e não só a reprodução de contextos comunicativos informais (p. 138).

Portanto, o Referencial Curricular para a Educação Infantil reafirma o oral como um dos domínios prioritários do ensino de língua portuguesa. Eleger a língua oral como 
conteúdo escolar exige o planejamento da ação pedagógica de forma a garantir, na sala de aula, atividades sistemáticas de fala, escuta e reflexão sobre a língua oral.

\section{O ensino do oral}

A constituição do oral como objetivo legítimo de ensino exige, portanto, antes de tudo, um esclarecimento das práticas orais de linguagem que serão exploradas na escola e uma caracterização das especificidades linguísticas e dos saberes práticos nelas implicados.

As pesquisas linguísticas apontam para uma concepção de oralidade e escrita como duas práticas sociais de uso da língua. Dessa forma, as relações entre elas se dão dentro de um continuum tipológico das práticas sociais de produção textual (MARCUSCHI,2002). As duas modalidades caracterizam-se como multissistêmicas, utilizam múltiplas linguagens, por exemplo, a oralidade serve-se da gestualidade, mímica, prosódica etc. e a escrita serve-se da cor, tamanho, forma das letras e dos símbolos, como também de elementos logográficos, icônicos e pictográficos, entre outros, para fins expressivos.

Essa práticas sociais apontam para os gêneros e aqui, segundo Schnweuly (2004), o desenvolvimento se dá por continuidade e ruptura: gêneros primários e secundários. $\mathrm{O}$ autor fala sobre a mudança que se opera com a entrada da criança na escola, com a reestruturação do sistema de produção de linguagem. Retomando e reinterpretando a sugestão de Bakhtin (1953/1995), que distingue gêneros primários "que se constituíram em circunstâncias de uma comunicação verbal espontânea - e gêneros secundários - que "aparecem em circunstâncias de uma comunicação cultural, mais complexa e relativamente mais evoluída, principalmente escrita: artística, científica, sociopolítica" (p. 281), podem-se definir as seguintes dimensões para os gêneros primários:

- troca, interação, controle mútuo pela situação;

- funcionamento imediato do gênero como entidade global controlando todo o processo, como uma só unidade; 
- nenhum ou pouco controle metalingüístico da ação lingüística em curso. (p. 281)

Já as particularidades de funcionamento dos gêneros secundários apontadas pelo autor são:

a) modos diversificados de referência a um contexto lingüisticamente criado. Com a complexificação dos gêneros e, sobretudo, com sua autonomização no que diz respeito ao contexto, aparece, cada vez mais, a necessidade de criar-se uma coesão interna, um fechamento interno, por assim dizer, do texto. Entre outras maneiras, isso se faz lingüisticamente pela criação de instrumentos lingüísticos que se referem a um contexto lingüisticamente criado pelo texto. Pensemos aqui nos complexos sistemas de retomadas anafóricas, nos organizadores textuais e nos sistemas temporais, mas, também, no que se refere à escrita, nos diferentes tipos de "topogramas" (ANIS 1988);

b) modos de desdobramento do gênero. Ontogeneticamente, os poucos estudos, ainda muito raros, sobre a metalinguagem das crianças de mais de dez anos, em especial no quadro da produção escrita, demonstram uma capacidade fortemente crescente de controlar seu próprio processo de produção de linguagem, por meio de "gêneros" especializados para essa função. Poderíamos quase dizer que os gêneros secundários criam seus duplos: gêneros, especializados por domínio, que servem à prescrição, à avaliação, mas também ao controle de sua produção.

c) ousarei uma última hipótese que desenvolverei em detalhes adiante: a gestão eficaz dos gêneros secundários pressupõe a existência e a construção de um aparelho psíquico de produção de linguagem que não funciona mais na "imediatez"-comunicação verbal espontânea, 
diz Bakhtin (1995), mas que pode se basear na gestão de diferentes níveis, relativamente autônomos (não se trata aqui de um modelo de modularidade inata, mas construída, fruto do desenvolvimento). Isso significa a existência de níveis de decisão, de operações discursivas transversais em relação aos gêneros.

O desenvolvimento dos gêneros secundários não se dá de forma espontânea, requer um outro tipo de intervenção nos processos de desenvolvimento, diferente do necessário para o desenvolvimento dos gêneros primários. No entanto, os gêneros secundários bebem na fonte dos primários. E essa mediação entre os gêneros primários e secundários exige uma metodologia de trabalho. Introduzir os gêneros orais públicos na Educação Infantil já prepara para a mediação também com a escrita.

Quando falamos em gêneros públicos, nos referimos, por exemplo, a um debate entre alunos, com temas apropriados para a idade. Imaginemos colocar em discussão o uso do refrigerante no lanche, todos os dias. Para isso, deveriam conversar em casa com os pais, discutir com os colegas. A professora mostraria o uso de justificativas, o que é defender uma opinião. Como se defende uma opinião. Finalmente, organizar um debate, em que as os alunos explicitassem as justificativas para a sua tomada de posição, gravando, naturalmente para a autoavaliação dos próprios alunos. Outra opção, trabalhar com os gêneros instrucionais, em que cada dia uma criança explica o funcionamento de determinado jogo. A própria contação de história, dando relevo para a sequência de ideias, as conclusões apontadas etc. Todos esses gêneros orais vão construindo elos profundos com a escrita formal, que é um gênero secundário. E quando se coloca a questão do desenvolvimento da oralidade, é imprescindível não enfocar o oral de maneira geral e trabalhar apenas os aspectos mais visíveis da fala, mas explorar diversas 
práticas orais de linguagem e as relações muito variáveis que estas mantêm com a escrita.

\section{Aquisição e gêneros}

A ação de falar realiza-se com a ajuda de um gênero que é um instrumento para agir linguisticamente.

Aprender a falar é apropriar-se dos gêneros. Sabemos que a capacidade de adquirir uma língua é uma característica específica da espécie humana, pois requer um sistema neurofisiológico particular, com órgãos e sistema nervoso apropriados. Mas, além do aparato físico, a aquisição requer a inserção no processo sócio-histórico. Se isolarmos a criança, mesmo com todos os órgãos perfeitos, ela não conseguirá desenvolver uma língua.

Para Scliar-Cabral (2003), são três os fatores de desenvolvimento da linguagem: o inato, a maturação, e o ambiental. No desenvolvimento pré-natal, ocorre a formação de neurônios e sua migração para as regiões apropriadas do cérebro, o hemisfério esquerdo. Em relação à maturação, os circuitos que ligam os diversos centros do sistema nervoso central não nascem prontos: os prolongamentos dos neurônios precisam ser recobertos por uma camada rica em proteínas, processo conhecido por mielinização, para que se estabeleçam as ligações de modo adequado e no momento certo.

Para que esta programação compulsória da espécie humana seja ativada, é necessária uma alavanca, ou seja, os dados deverão ser captados por um canal de entrada e reconstruídos pela percepção: o canal de entrada privilegiado pela espécie humana para captar a linguagem verbal oral é o auditivo, mas ele é reforçado pelas informações do chamado canal prioprioceptivo (que envia informações ao cérebro sobre os movimentos realizados por nosso corpo, no caso, os realizados pelo aparelho fonador da criança que está ensaiando suas primeiras falas) e também pela visão.

Uma vez que os programas inatos para o desenvolvimento da linguagem oral e sua maturação precisam ser ativados pela interação verbal, sobressai 
a importância dos fatores ambientais, desde aqueles que cercam a gestante, os primeiros meses de vida do infante, até o processo de socialização. O fato de uma criança ouvir desde cedo narrativas recontadas ou lidas ativa positivamente o desenvolvimento de esquemas mentais.

A aquisição, como vimos, evolui de uma participação menor para uma maior. Pela mediação de um interlocutor mais experiente, que auxilia através da seleção de elementos linguísticos, isto é, através do uso de suas funções psicológicas, a criança passa a adquirir uma certa autonomia no uso da língua. A construção do conhecimento depende da troca existente na comunidade à qual pertence a criança e dos ambientes de aprendizagem criados como estratégias para a aprendizagem. E a escola como ambiente particular de aprendizagem deve estar atenta para as práticas educativas que melhor desenvolvam as capacidades linguístico-cognitivas dos educandos.

Segundo Oliveira (2005), a narrativa da criança, inicialmente, é um relato enumerativo de origem perceptiva e motora, reunindo objetos segundo a relação deles na atividade. Desse modo, não apresenta a correspondência necessária entre causa e efeito, entre meio e fim, e os elementos de conexão mais presentes são: aí e depois. Ora, a escuta da história e a tentativa de recontá-la são estratégias importantíssimas na formação de um pensamento mais linguisticamente mais estruturado.

Bakhtin (1995) afirma que a criança aprende a falar através dos gêneros. E isso nós constatamos, pois, no dia a dia, os gêneros mesclam-se naturalmente, desde a mais tenra idade. Nos diversos gêneros discursivos, temos apenas o discurso em que se narra, se instruí, se lista, se emite opinião, se dialoga, tudo de uma forma dinâmica e interligada. Explorar na escola os gêneros é trazer para a reflexão algo que já faz parte de seu cotidiano. A tarefa da escola é chamar atenção para a reflexão do uso. 


\section{O ensino do oral na escola.}

Em nossa pesquisa "A construção da textualidade na fala infantil", dentre outros aspectos, buscamos observar os dados de nosso corpora, tendo em vista apontar os gêneros textuais que se apresentam na fala de crianças de 3 a 5 anos, em ambiente escolar. Além disso, tentamos compreender o processo de textualidade nas produções orais infantis, observando a função dos fatores de textualidade já presentes no repertório lingüístico das crianças e propondo estratégias metodológicas que privilegiem o conhecimento de uma maior variedade de elementos responsáveis pela tessitura do texto.

Aliada às orientações dos PCN, em que as produções textuais se tornam objeto de ensino, temos a teoria dos Gêneros Textuais, que redimensiona a noção de texto, destacando sua função sócio-comunicativa. Isso significa que, ao ser explorado em sala de aula, o texto passa a ser visto como objeto inserido nas diversas práticas sociais atravessadas pela linguagem. Isso é reforçado por Marcuschi (2002) quando afirma que: os gêneros textuais são fenômenos históricos, profundamente vinculados à vida cultural e social. Fruto de trabalho coletivo, os gêneros contribuem para ordenar e estabilizar as atividades comunicativas do dia-a-dia. A importância dada aos gêneros textuais quanto ao seu papel nas atividades sociocomunicativas acentua a ideia de se trabalhar as diversas variedades textuais que habitam o campo da oralidade e da escrita, oscilando do grau mais coloquial ao mais formal. Toda essa heterogeneidade amplifica as possibilidades de colocar a criança em contato com os diferentes domínios que a língua abarca. É nesse processo que o professor se firma enquanto agente modificador das atividades em torno do texto, que deixa de ser somente pretexto para análise linguística, ganhando lugar de reflexão sobre seu caráter social.

\section{Dados de análises}

Em nosso corpus, existem dados de gravação de crianças em pré-escolas municipais. Os gêneros que 
predominam em sala são: o diálogo e a contação de histórias. O diálogo espontâneo em que a criança fala com o colega e com a professora. Não existe reflexão sobre essa fala. Não existe escuta da própria fala ou da fala alheia. Não existe a autoavaliação da oralidade. Quanto à contação, trouxemos dois exemplos recorrentes:

Após a leitura de uma história, a professora solicita que os alunos a comentem. Esse momento acontece já perto do horário de as crianças irem para casa.

\begin{tabular}{|l|l|}
\hline Prof. & $\begin{array}{l}\text { Vá, conte. O que foi que aconteceu com o } \\
\text { príncipe? }\end{array}$ \\
\hline Jonathan & Um lindo príncipe. \\
\hline Prof. & $\begin{array}{l}\text { Como é o nome dessa historinha aí? Historinha de } \\
\text { quê? }\end{array}$ \\
\hline Várias crianças & $\begin{array}{l}\text { (falas simultâneas)) A Bela e a Fe:ra. A Fera e a } \\
\text { Bela. }\end{array}$ \\
\hline Prof. & $\begin{array}{l}\text { A Bela e a Fera. Aí o que foi que aconteceu? A Fera } \\
\text { se transformou em quê? }\end{array}$ \\
\hline Felipe & Na princesa. \\
\hline Prof. & A fera se transformou em uma princesa, foi? \\
\hline Criança & Não. \\
\hline Prof. & Não foi num príncipe não? \\
\hline Várias crianças & FOI! \\
\hline & As crianças se dispersam. \\
\hline
\end{tabular}

Em outra semana:

\begin{tabular}{|l|l|}
\hline Felipe & Era uma vez. \\
\hline Prof. & Era uma vez quem? \\
\hline Felipe & Um lobo mau. ((?)) \\
\hline Criança & Uma fera. \\
\hline Prof. & $\begin{array}{l}\text { Vamo pará até aí, vai. (.) Pode não, mexer aí, Cíntia! } \\
\text { Calma, vai terminar rasgando o livro! Peraí, dá licença! } \\
\text { Dá licença. ((a professora toma o livro das crianças, que } \\
\text { se amontoavam para vê-lo)) Felipe, vai, a gente vai olhar } \\
\text { e Felipe vai contar. O que foi que aconteceu? ((?)) Quem } \\
\text { é esse senhor aqui? ((apontando para uma gravura do } \\
\text { livro)) Quem é ele na historinha que a tia contou? }\end{array}$ \\
\hline
\end{tabular}




\begin{tabular}{|l|l|l|l|}
\hline Algumas crianças & O pai de BELA & & \\
\hline & $\begin{array}{l}\text { (recomeça uma discussão e a história é } \\
\text { interrompida) }\end{array}$ & & \\
\hline
\end{tabular}

A organizaçãodohoráriodivide-seemalimentação, tarefas motoras (cobrir letras, usar o abecedário), aquisição de escrita, jogos, intervalo, lanche, repouso, tarefas para uso da criatividade (pintura, massa de modelar, desenho), matemática (ou outro objeto de conhecimento), higiene, alimentação, volta para casa. Não são todos os dias em que há histórias, e, muitas vezes, esse momento se dá próximo ao momento do retorno para casa. Pelo que pudemos observar, não há um planejamento, uma sequência, apenas a escolha de um livro pela professora ou então o pedido de que alguém conte uma história. Como vimos nos recortes, a história nunca se efetiva; há indícios, começos, que se desfazem no decorrer da experiência. Com isso, a vivência dessas crianças com o gênero história se transfere para um momento sempre posterior.

O texto oral aparece sem uma preparação prévia devido à falta de uma sistematização do próprio docente. A primeira conclusão a que chegamos é a de que não é possível desenvolver um texto se não há um ambiente favorável para isso. Esse ambiente é o primeiro passo para a entrada no mundo das histórias. Remetendo aos dados aqui apresentados, comprovamos a falta de sistematização de ensino do/com o texto oral na medida em que não se percebe quase nenhuma diferença entre a maneira como as produções orais das crianças são conduzidas no ambiente caseiro e a maneira como os textos orais das crianças são tratados em sala de aula. Em ambos os casos, o texto falado é reduzido a estratégias espontaneístas, sem objetivos bem definidos para serem alcançados. O discurso oral requer preparação, automonitoração e capacidade de encadear os turnos. Exige um trabalho efetivo da escola. 


\section{Perspectivas para o ensino da oralidade}

Como foi visto nos recortes de análises, a preocupação como oral ainda não se encontra no centro da prática pedagógica. O que fazer para mudar essa situação? Um caminho pode ser a pedagogia dos gêneros orais na escola.

Schneuwly (1994) sugere que, do ponto de vista da construção dos discursos e da linguagem pela criança, podemos tomar os gêneros do discurso como megainstrumentos, isto é, instrumentos de mediação semiótica complexos que implicariam, por si próprios, a construção de instrumentos menos complexos nele envolvidos, no nível da linguagem e do pensamento. É justamente neste sentido que os gêneros do discurso, implicando aspectos temáticos, composicionais, enunciativos e linguísticos em si mesmos, são uma poderosa ferramenta de ensinoaprendizagem de línguas.

Segundo os autores, gêneros pertencentes a uma mesma esfera social de comunicação, apresentando possíveis semelhanças em suas situações de produção, compartilharão outros aspectos entre si a nível composicional e temático, embora com diferentes graus de complexidade. Neste sentido é que se autorizam a propor agrupamentos de gêneros.

Numa reflexão ainda bastante aberta a sugestões e modificações, os autores mencionam cinco destes agrupamentos, definidos pelo seu domínio social de comunicação privilegiado, que, por sua vez, tanto determinaria aspectos composicionais e temáticos, denominados pelos autores de aspectos tipológicos, como exigiria do enunciador certas capacidades de linguagem dominantes. São eles:

- AGRUPAMENTO DA ORDEM DO RELATAR

- ligado ao domínio social da comunicação voltado à documentação e memorização das ações humanas, exigindo uma representação pelo discurso de experiências vividas situadas no tempo (relatos de experiência vivida, diários 
íntimos, diários de viagem, notícias, biografias, relato histórico, etc.);

- AGRUPAMENTO DA ORDEM DO NARRAR

- ligado ao domínio social da cultura literária ficcional, caracteriza-se pela mimesis da ação através da criação da intriga no domínio do verossímil (contos de fadas, fábulas, lendas, ficção científica, romance, etc.);

- AgRUPAMENTO DA ORDEM DO ARGUMENTAR - ligado ao domínio social da comunicação voltado à discussão de problemas sociais controversos, exige a sustentação, refutação e negociação de tomadas de posição (diálogo argumentativo, carta de reclamação, debate regrado, editorial, ensaio argumentativo, etc.);

- AGRUPAMENTO DA ORDEM DO EXPOR

- ligado ao domínio social da comunicação voltado à transmissão e construção de saberes, exige a apresentação textual de diferentes formas dos saberes (texto expositivo, conferências, seminários, resenhas, artigos, etc.);

- AGRUPAMENTO DA ORDEM DO DESCREVER AÇÕES - ligado ao domínio social da comunicação voltado às instruções e prescrições, exige a regulação mútua de comportamentos (instruções de uso, instruções de montagem, receitas, regulamentos, regras de jogo, etc.) (p. 67).

Ainda na opinião dos autores, cada um destes e todos os agrupamentos teriam de ser trabalhados em cada série escolar, variando-se seja o gênero selecionado para exploração, seja o grau de profundidade da abordagem de um gênero, garantindo-se construções cada vez mais complexas de linguagem, num processo de ensinoaprendizagem espiral que tomaria a complexificação como dinâmica para a progressâo didática.

A essa altura a pergunta que se faz é: quais gêneros ensinar? A maioria das crianças possui um domínio 
razoável do oral quando entra para a escola. Na Educação Infantil e nos primeiros anos do ensino fundamental, os professores devem consolidar os usos informais do português oral e introduzir novos usos relacionados a esse lugar de comunicação particular que é a sala de aula. Na Educação Infantil, é possível já introduzir os diferentes agrupamentos, elegendo alguns gêneros e adaptandoos às particularidades da idade: Do relatar: experiência vivida, diários de viagem, notícias, biografias; Do narrar: contos de fadas, fábulas, lendas; Do argumentar: diálogo argumentativo; Do descrever: instruções de uso, receitas, regras de jogo. Todos esses gêneros já fazem parte do cotidiano de qualquer criança.

\section{Conclusão}

Vimos que ensino oral é previsto no Referencial Curricular para a Educação Infantil. Vimos também que a Pré-Escola ainda não conseguiu assimilar, na prática, um trabalho mais sistematizado no campo da oralidade, nem mesmo a contação de história encontra um espaço ordenado no dia a dia da sala de aula. Ao lado dessas constatações, o trabalho com os gêneros parece uma alternativa viável e promissora, dando mostras de ser uma proposta metodológica para a inclusão da oralidade como objeto de ensino na Pré-Escola. Eleger a língua oral como conteúdo escolar exige o planejamento da ação pedagógica de forma a garantir, na sala de aula, atividades sistemáticas de fala, escuta e reflexão sobre a língua oral. $\mathrm{Na}$ verdade, ainda não há respostas definitivas para as questões propostas acima. Certamente, a prática nos indicará os caminhos a seguir. 


\section{Referências}

BAKHTIN, Mikhail. Marxismo e filosofia da linguagem. $7^{\mathrm{a}} \mathrm{ed}$., São Paulo:Hucitec, 1995.

BRASIL. Ministério da Educação e do Desposto. Secretaria de Educação Fundamental. Referencial curricular nacional para a educação infantil. Brasília: MEC/SEF, 1998.

BRASIL. Lei de diretrizes e bases da educação nacional. Brasília: MEC, 1996

DOLZ, Joaquim, SCHNEUWLY, Bernard. O oral como texto: um caminho para o ensino da linguagem oral. In: DOLZ, Joaquim, SCHNEUWLY, Bernard. Gêneros orais e escritos na escola. Campinas, SP: Mercado de Letras, 2004.

MARCUSCHI, Luiz Antonio. Gêneros textuais: definição e funcionalidade. In: DIONÍSIO, A. P., MACHADO, A. R. , BEZERRA, M. A. (Orgs.) Gêneros textuais e ensino. Rio de Janeiro: Editora Lucerna, 2002.

OLIVEIRA, Zilma Ramos de. Educação infantil: fundamentos e métodos. $2^{\text {a }}$ ed. São Paulo: Cortez, 2005

SCLIAR-CABRAL, Leonor. Guia Prático de Alfabetizaçâo. São Paulo: Contexto, 2003 